\title{
PA from an H5N1 highly pathogenic avian influenza virus activates viral transcription and replication and induces apoptosis and interferon expression at an early stage of infection
}

Qiang Wang ${ }^{1,2+}$, Shijian Zhang ${ }^{2,3,4+}$, Hongbing Jiang ${ }^{2}$, Jinlan Wang ${ }^{2}$, Leiyun Weng ${ }^{2}$, Yingying Mao ${ }^{2}$, Satoshi Sekiguchi ${ }^{5}$, Fumihiko Yasui ${ }^{5}$, Michinori Kohara ${ }^{5}$, Philippe Buchy ${ }^{6}$, Vincent Deubel ${ }^{6}$, Ke Xu$^{1}$, Bing Sun ${ }^{1}$ and Tetsuya Toyoda $2,5,7^{*}$

\begin{abstract}
Background: Although gene exchange is not likely to occur freely, reassortment between the H5N1 highly pathogenic avian influenza virus (HPAIV) and currently circulating human viruses is a serious concern. The PA polymerase subunit of H5N1 HPAIV was recently reported to activate the influenza replicon activity.

Methods: The replicon activities of PR8 and WSN strains (H1N1) of influenza containing PA from HPAIV A/Cambodia/P0322095/2005 (H5N1) and the activity of the chimeric RNA polymerase were analyzed. A reassortant WSN virus containing the H5N1 Cambodia PA (C-PA) was then reconstituted and its growth in cells and pathogenicity in mice examined. The interferon promoter, TUNEL, and caspase 3, 8, and 9 activities of C-PA-infected cells were compared with those of WSN-infected cells.
\end{abstract}

Results: The activity of the chimeric RNA polymerase was slightly higher than that of WSN, and C-PA replicated better than WSN in cells. However, the multi-step growth of C-PA and its pathogenicity in mice were lower than those of WSN. The interferon promoter, TUNEL, and caspase 3, 8, and 9 activities were strongly induced in early infection in C-PA-infected cells but not in WSN-infected cells.

Conclusions: Apoptosis and interferon were strongly induced early in C-PA infection, which protected the uninfected cells from expansion of viral infection. In this case, these classical host-virus interactions contributed to the attenuation of this strongly replicating virus.

Keywords: Influenza virus, PA, Transcription, Replication, Apoptosis, Interferon

\footnotetext{
* Correspondence: toyoda_tetsuya@yahoo.co.jp

${ }^{\dagger}$ Equal contributors

${ }^{2}$ Units of Viral Genome Regulation, the Key Laboratory of Molecular Virology

\& Immunology, Institut Pasteur of Shanghai, Chinese Academy of Sciences, 411 Hefei Road, 200025, Shanghai, P. R. China

${ }^{5}$ Department of Microbiology and Cell Biology, Tokyo Metropolitan Institute of Medical Biology, 3-18-22 Honkomagome, Bunkyo-Ku, Tokyo 113-8613, Japan

Full list of author information is available at the end of the article
} 


\section{Background}

Influenza A viruses cause disease in humans, pigs, other mammals, and birds [1]. The genomes of influenza A viruses are composed of 8 negative-sense single-stranded RNA segments; this segmented genome allows gene reassortment between viruses in co-infected cells to produce new viruses. Reassortment of influenza A virus genes caused the deadly H2N2 "Asian flu" and the H3N2 "Hong Kong flu" pandemics in 1957 and 1968, respectively. During these pandemics, the avian virus PB1, $\mathrm{HA}$ and NA, or PB1 and HA genes, respectively, were introduced into circulating human viruses $[2,3]$. The last pandemic strain, the novel swine-origin influenza virus A/H1N1 (S-OIV), carries PB2 and PA genes of avian origin [4]. In addition to the S-OIV pandemic flu, H5N1 highly pathogenic avian influenza viruses (HPAIV) have caused severe or fatal disease in humans in Asia, the Middle East, and Africa since their emergence in Hong Kong in 1997 (WHO, http://www.who.int/csr/disease/ avian_influenza/en/). The H5N1 influenza virus ribonucleoprotein complex (RNP) contributes to viral pathogenesis in chickens $[5,6]$. Influenza viruses with high polymerase activity have also shown high pathogenicity $[7,8]$. These lines of evidence suggest that the influenza RNA-dependent RNA polymerase ( $R d R p)$ contributes to its pathogenesis.

Influenza A virions contain 8 negative-sense singlestranded RNA genome segments and RdRp [9]. Genome segments 1, 2, and 3 encode the RdRp subunits PB2, PB1, and PA, respectively. Segment 4 encodes hemagglutinin (HA), segment 5 nucleoprotein (NP), segment 6 neuraminidase (NA), segment 7 matrix protein 1 (M1) and an ion channel (M2), and segment 8 non-structural protein 1 (NS1) and nuclear export protein (NEP). A second open reading frame of segment 2 encodes PB1-F2 in some strains.

The RdRp subunit PB1 is the core subunit of the RdRp complex and mediates RNA polymerization [10-12], while PB2 is the cap-binding subunit [13-15] and PA has capdependent endonuclease activity [16-20]. Influenza virus RdRp catalyzes both transcription of viral mRNA and replication of the viral genome. Influenza transcription is a prototype of primer-dependent initiation. The viral RdRp binds to the cap- 1 structures of host mRNAs and cleaves off 9 to 15 nucleotides to generate primers for viral transcription, a process known as "cap snatching" [13,21-23]. The internal initiation mechanism of influenza virus genome replication was recently elucidated [24,25].

H5N1 HPAIV does not efficiently adapt to transmission to humans [26]. However, once it does infect humans, it results in high mortality of approximately $60 \%$ [27,28]. Although some genomic combinations, such as those between human H3N2, avian H5N1, and horse H7N7 or between human H3N2 and avian H2N2, may be incompatible [29-32], reassortment between H5N1 HPAIV, which is epizootic among poultry almost worldwide [33], and currently circulating human influenza viruses, including the pandemic S-OIV and seasonal influenza viruses (H1N1 and H3N2), is one of the most important potential threats for the next pandemic. Kashiwagi et al. recently reported that the PA of H5N1 HPAIV activated the polymerase activity by enhancing promoter binding [34]. Multiple functions of PA in addition to promoter binding, such as transcription and replication $[9,18]$, endonuclease activity $[16,17,19,20,35]$, cap binding [19], protease activity [36], proteolysis induction [37], pathogenesis in mice [38], and thermal sensitivity of RNP [39], have been identified.

In this paper, we describe the activation of the polymerase activity of A/Puerto Rico/8/1934 (PR8, H1N1) and A/WSN/1933 (WSN, H1N1) RNPs by the H5N1 HPAIV PA of A/Cambodia/P0322095/2005, which was isolated from a Cambodian victim [40], and the reconstitution of the chimeric virus to analyze the effect of this H5N1 PA in the background of WSN, a well-studied mouse influenza infection model. We found a discrepancy between the viral polymerase activity and proliferation efficiency in cells and its pathogenesis in mice. We then analyzed the mechanism of the attenuation and the low pathogenicity of WSN carrying H5N1 PA.

\section{Results}

\section{Effect of H5N1 Cambodia PA on the PR8 and WSN replicons and in vitro RdRp activity}

We first examined the replicon activity in $293 \mathrm{~T}$ cells of a chimeric PR8 RNP containing H5N1 Cambodia PA (Figure 1A). Influenza replicon activity was measured as previously described [41,42]. The replicon activity was about $200.0 \pm 8.2 \%$ that of the PR8 RNP (Student's $t$; $\mathrm{p}<0.005$ ), while the Cambodia RNP showed $43.8 \pm 2.9 \%$ of the replicon activity of the PR8 RNP ( $<<0.005)$. The expression of $\mathrm{RdRp}$ and NP in the transfected cells was confirmed by western blotting (Additional file: Figure S1).

As we found 2-fold activation of the PR8 replicon by H5N1 Cambodia PA, we purified both PR8 RdRp and a chimeric RdRp (PR8PB2-PR8PB1-H5N1 Cambodia PA) in order to investigate the effect of the H5N1 Cambodia PA on RdRp activity in vitro. Sodium dodecyl sulfatepolyacrylamide gel electrophoresis (SDS-PAGE) showed that H5N1 Cambodia PA migrated to a higher position than did PR8PA; the Cambodia PA band almost overlapped with that of $18 \times$ HisPR8PB2 (Figure 1B). The identity of H5N1 Cambodia PA was confirmed by western blotting against PA (Figure 1C).

We next compared the activities of the purified RdRps in vitro. We tested the transcription activity using v84 and globin mRNA primers (Figure 1D and E, mRNA), and replication activity using v84 and c84 with and 
A

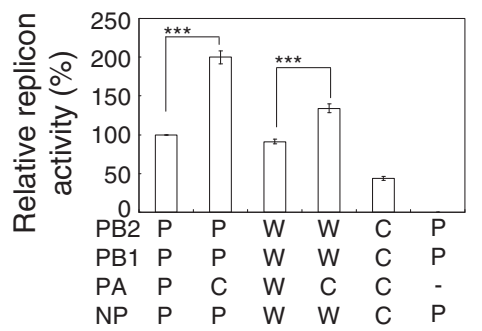

B

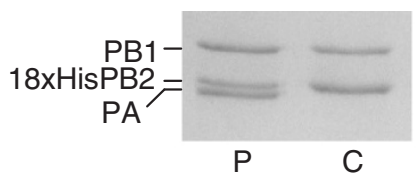

C

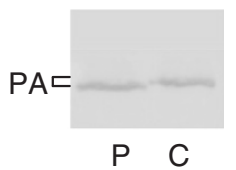

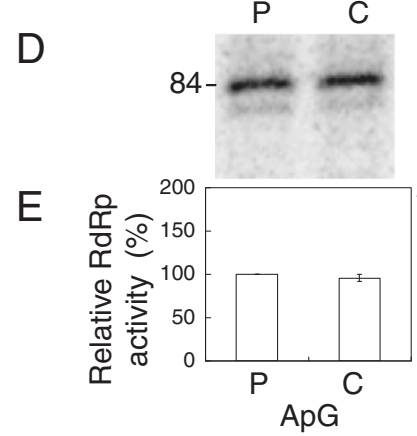
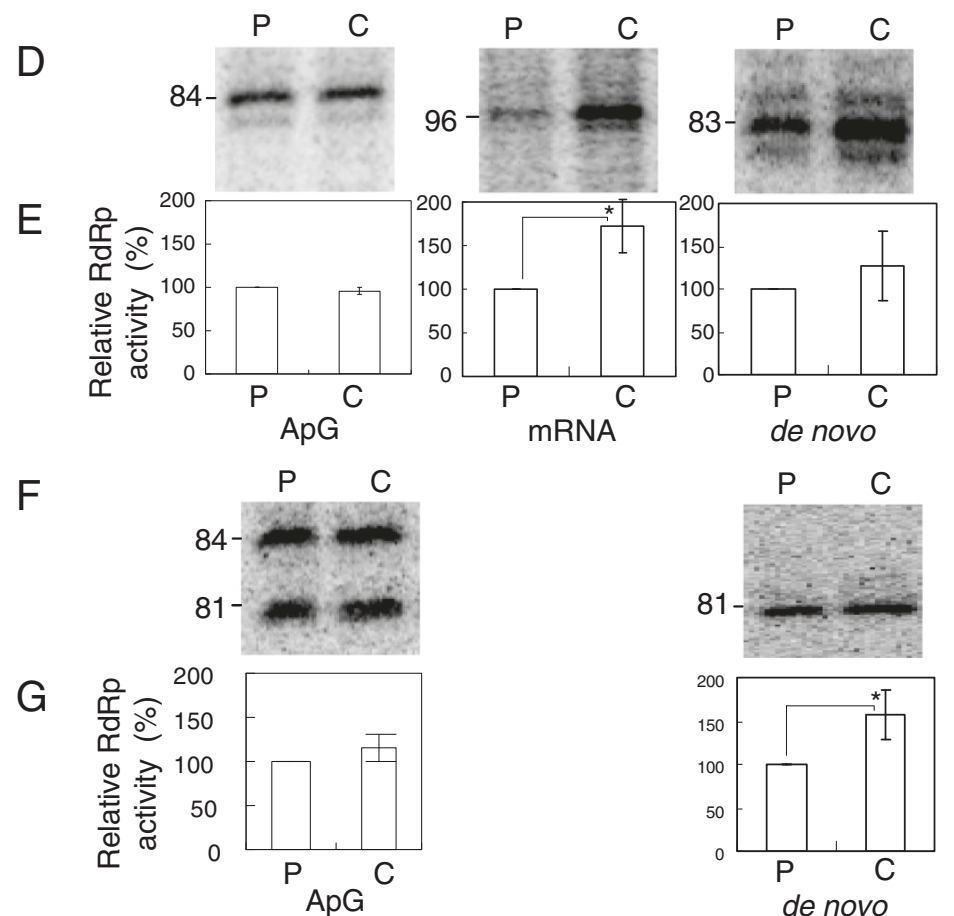

Figure 1 Replicon and in vitro RNA-dependent RNA polymerase (RdRp) activities of the chimeras of H5N1 Cambodia PA with PR8 and WSN. A: Replicon activity of the chimeric influenza virus ribonucleoproteins (RNPS) of WSN and PR8 with H5N1 Cambodia PA. The relative replicon activities of WSN and PR8 with H5N1 Cambodia PA in 293 T cells were compared with those of WSN and PR8. The combination of PB2, PB1, PA, and NP is indicated below the graph. W, WSN; P, PR8; C, H5N1 Cambodia. As a negative control, PR8 replicon without PA was used. B: Purified influenza virus PR8 RdRp (P) and PR8PB2-PR8PB1-C-PA RdRp (C). Each RdRp (5 pmol) was subjected to sodium dodecyl sulfatepolyacrylamide gel electrophoresis (SDS-PAGE) on 7.5\% gels and Coomassie brilliant blue staining. The positions of PB1, 18×His-PB2, and PA are indicated on the left. C: Western blot of the purified influenza virus chimeric RdRp. Each RdRp (5 pmol) was electro-blotted onto the nitrocellulose membrane. The PA was detected by western blotting with anti-PA antibodies. The position of PA is indicated on the left. D and E: Comparison of the chimeric RdRp activities in in vitro transcription and replication of v84 with those of PR8. The v84 model template RNA (200 nM) was transcribed by PR8RdRp (P) or PR8PB2-PR8PB1-C-PA RdRp (C) with or without (de novo) 0.1 mM ApG (ApG) or $0.5 \mu g$ globin mRNA (mRNA). $\mathbf{F}$ and $\mathbf{G}$ : Comparison of chimeric RdRp activity in in vitro replication of c84 with that of PR8. The c84 model template RNA was incubated with or without ApG (de novo). Products were analyzed by PAGE on 6\% gels containing $8 \mathrm{M}$ urea and the images analyzed with a Typhoon Trio plus. Examples of the images are shown in D and F. The size of the product RNA is indicated on the left. The mean and standard deviation (error bar in the graph) of the polymerase activity relative to that of PR8 RdRp were calculated from 2 independent measurements of 3 different RdRp preparations. Statistical significance was evaluated with Student's $t$-test. ${ }^{*} p<0.05,{ }^{* * *} p<0.005$.

without the dinucleotide primer ApG (Figure 1D, E, F, and G). ApG-primed and de novo initiation of v84 transcription produced 84- and 83-nt products, respectively, while globin mRNA-primed transcription produced 96nt products. Because virion RdRp uses 10-15 nucleotide primers to initiate from the $\mathrm{C}$ at the 2 nd position from the 3 ' end of the genome [18,22], the 96-mer products were assigned to the transcripts from the 13th $\mathrm{G}$ next to the 12 th $U$ of the cap- 1 structure $\left(\mathrm{m}^{7} \mathrm{GmACACUUG-}\right.$ CUUUU) of rabbit $\beta$-globin mRNA (GenBank; M10843). The mean and standard deviation (error bar in the graph) of the polymerase activity relative to that of PR8 RdRp were calculated from 2 independent measurements of 3 different $\mathrm{RdRp}$ preparations. The relative 
ApG-primed replication activity of the chimeric $R d R p$ was $95.9 \pm 4.5 \%$ of that of PR8 RdRp, while its de novo replication activity was $126 \pm 40 \%$ of that of PR8 RdRp. The chimeric $\mathrm{RdRp}$ produced $171 \pm 31 \%(\mathrm{p}<0.05)$ of the amount of 96-nt transcription products. ApGprimed initiation of c84 produced 84- and 81-nt products, while de novo initiation produced 81-nt products. The relative replication activity of ApG-primed initiation of $c 84$ by the chimeric RdRp was $116 \pm 16 \%$ of that by PR8 RdRp, while its de novo initiation was $156 \pm 29 \%$ of that by PR8 RdRp $(\mathrm{p}<0.05)$. We thus confirmed that H5N1 Cambodia PA enhanced both the transcription and replication activities of PR8 RdRp.

Before reconstituting WSN carrying H5N1 Cambodia PA, we tested the effect of H5N1 Cambodia PA on the WSN replicon (Figure 1A). WSN replicon activity $(91.3 \pm 3.2 \%)$ was similar to that of PR8. The replicon activity of WSN containing the H5N1 Cambodia PA (which was $133.9 \pm 5.8 \%$ of that of the PR8 replicon) was about 1.5-fold higher than that of the WSN replicon $(\mathrm{p}<0.005)$. Therefore, we also observed an activation effect of H5N1 Cambodia PA on the WSN replicon.

\section{Effect of H5N1 Cambodia PA on virus growth in MDCK} cells, chicken embryo fibroblasts (CEF), and Vero cells Next, we tested whether the RdRp activation effect of H5N1 Cambodia PA affected virus growth. As the RdRp subunits of PR8 and WSN are highly homologous, with 96, 97, and 98\% amino acid identity between the PB2, PB1, and PA genes, respectively, and as the activation effect of H5N1 Cambodia PA was confirmed in both the WSN and PR8 replicons, we used a WSN reconstitution system to analyze the effect of H5N1 Cambodia PA in H1N1 virus. The WSN virus carrying H5N1 Cambodia PA (C-PA) was reconstituted successfully. First, we compared the multi-step growth of C-PA with that of WSN in MDCK, CEF, and Vero cells.

In MDCK cells, the C-PA titer was always lower than that of WSN and plateaued $\left(4.7 \pm 0.2 \times 10^{4} \mathrm{PFU} / \mathrm{mL}\right)$ $16 \mathrm{hr}$ post-infection (pi), while the WSN titer was $2.2 \pm 0.03 \times 10^{5} \mathrm{PFU} / \mathrm{mL} 16 \mathrm{hr}$ pi and plateaued $\left(5.6 \pm 1.6 \times 10^{6} \mathrm{PFU} / \mathrm{mL}\right) 36 \mathrm{hr}$ pi (Figure $\left.2 \mathrm{~A}\right)$. The C-PA titer in MDCK cells $60 \mathrm{hr}$ pi was significantly higher than that of WSN $(p<0.001)$. The titers of C-PA and WSN in CEF did not plateau even $60 \mathrm{hr}$ pi. However, the C-PA titer $60 \mathrm{hr}$ pi $\left(7.1 \pm 1.4 \times 10^{5} \mathrm{PFU} / \mathrm{mL}\right)$ was about half of that of WSN $\left(1.3 \pm 0.4 \times 10^{6} \mathrm{PFU} / \mathrm{mL}\right)$, a statistically significant difference $(\mathrm{p}<0.001$, Figure $2 \mathrm{~B})$. We therefore observed a discrepancy between the effects of H5N1 Cambodia PA on RdRp activity and on virus growth in MDCK and CEF cells. However, the C-PA titer in Vero cells between $24 \mathrm{hr}$ and $60 \mathrm{hr}$ pi was significantly higher than that of WSN $(\mathrm{p}<0.05$, Figure $2 \mathrm{C})$. Both titers plateaued at $5.6 \pm 0.1 \times 10^{5} \mathrm{PFU} / \mathrm{mL} 70 \mathrm{hr}$ pi.
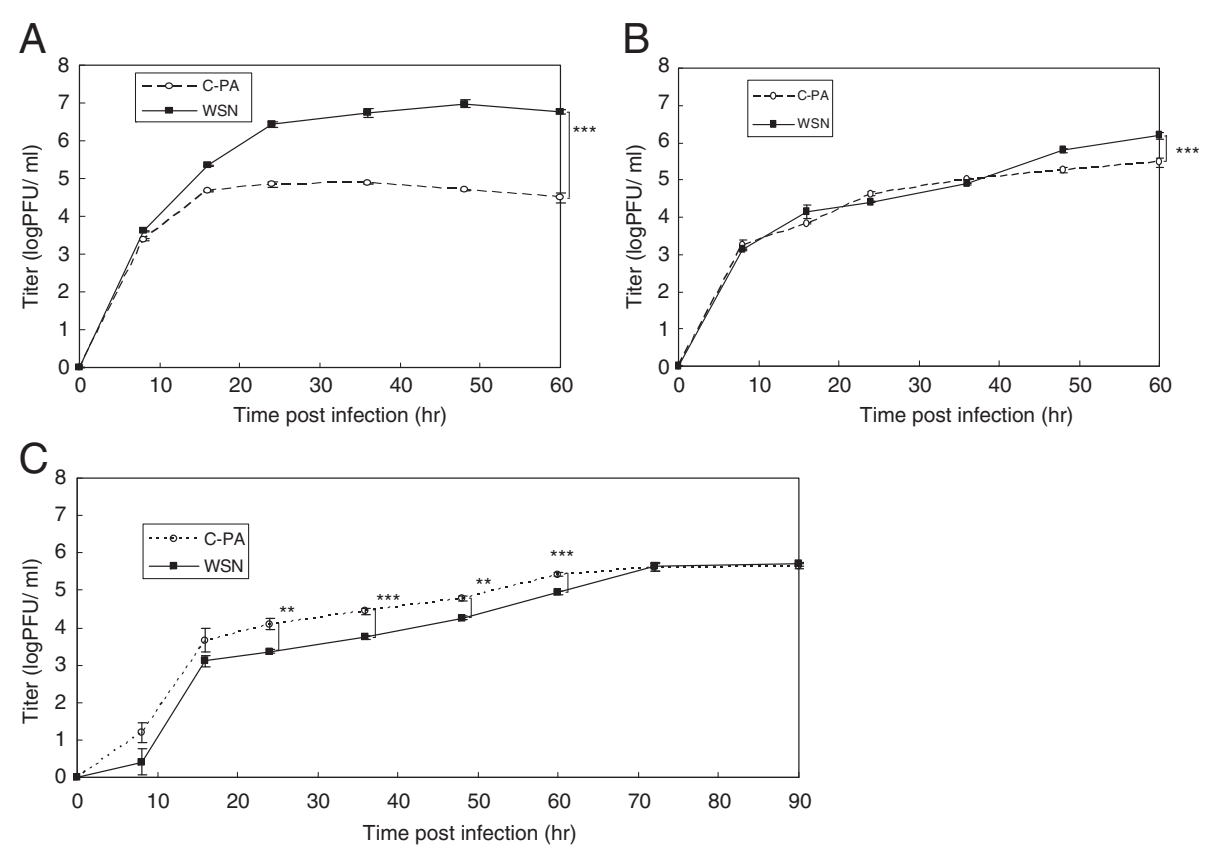

Figure 2 Multi-step growth curves of C-PA and WSN in infected cells. MDCK (A), chicken embryo fibroblast (CEF) (B), and Vero (C) cells were infected with C-PA or WSN at a multiplicity of infection (MOI) of 0.01. Viruses were harvested 8, 16, 24, 36, 48, and $60 \mathrm{hr}$ (additional $72 \mathrm{and} 90 \mathrm{hr}$ for Vero cells) after infection and their titers on MDCK cells measured by a plaque-formation assay. The mean and standard deviation (error bar in the graph) of each plaque titer were calculated from 3 independent experiments. Statistical significance was evaluated with Student's $t$-test. ${ }^{* *} p<0.01,{ }^{* * *} p<0.005$. 
No cytopathic effect was apparent in Vero cells (data not shown).

We next compared single-step growth of C-PA and WSN in MDCK and Vero cells (Figure 3). The C-PA titers in both MDCK and Vero cells between 4 and $12 \mathrm{hr}$ pi were higher than those of WSN. The C-PA titer in MDCK cells $12 \mathrm{hr}$ pi $\left(1.6 \pm 0.9 \times 10^{6} \mathrm{PFU} / \mathrm{mL}\right)$ was significantly higher than that of WSN $\left(1.3 \pm 0.7 \times 10^{5} \mathrm{PFU} / \mathrm{mL}\right)$ $(\mathrm{p}<0.005$, Figure 3A). The C-PA titer in Vero cells $12 \mathrm{hr}$ pi $\left(1.6 \pm 0.9 \times 10^{5} \mathrm{PFU} / \mathrm{mL}\right)$ was significantly higher than that of WSN $\left(2.9 \pm 0.2 \times 10^{4} \mathrm{PFU} / \mathrm{mL}\right)(\mathrm{p}<0.05$, Figure 3B). The growth of C-PA in both MDCK and Vero cells plateaued $6 \mathrm{hr}$ pi. WSN growth in Vero cells plateaued $8 \mathrm{hr}$ pi, while its titer in MDCK cells continued to increase up to $12 \mathrm{hr}$ pi.

\section{Pathogenicity of the C-PA virus in mice}

We also examined the pathogenicity of C-PA in mice. The $\mathrm{LD}_{50}$ for mouse nasal infection was calculated from the survival rate of the infected mice by the method of Reed and Münch (Figure 4) [43]. The $\mathrm{LD}_{50}$ values of $\mathrm{C}$-PA and WSN were $5 \times 10^{5} \mathrm{PFU}$ and $1 \times 10^{4} \mathrm{PFU}$, respectively. The pathogenicity of C-PA is therefore lower than that of WSN, despite its higher RdRp activity, both in cell culture (as reflected by the multi-step growth) and in mice.

We thus confirmed the discrepancy between the RdRp activity and pathogenicity both in cells (virus titer) and in mice. The genome sequence of the C-PA stock was confirmed to be identical to that of the genome reconstitution plasmids.

\section{Interferon induction}

Because the multi-step growth activity of C-PA was lower than that of WSN in MDCK and CEF cells but better in Vero cells, and because the single-step growth activity of C-PA was better than that of WSN in both MDCK and Vero cells, we examined the effect of C-PA

A

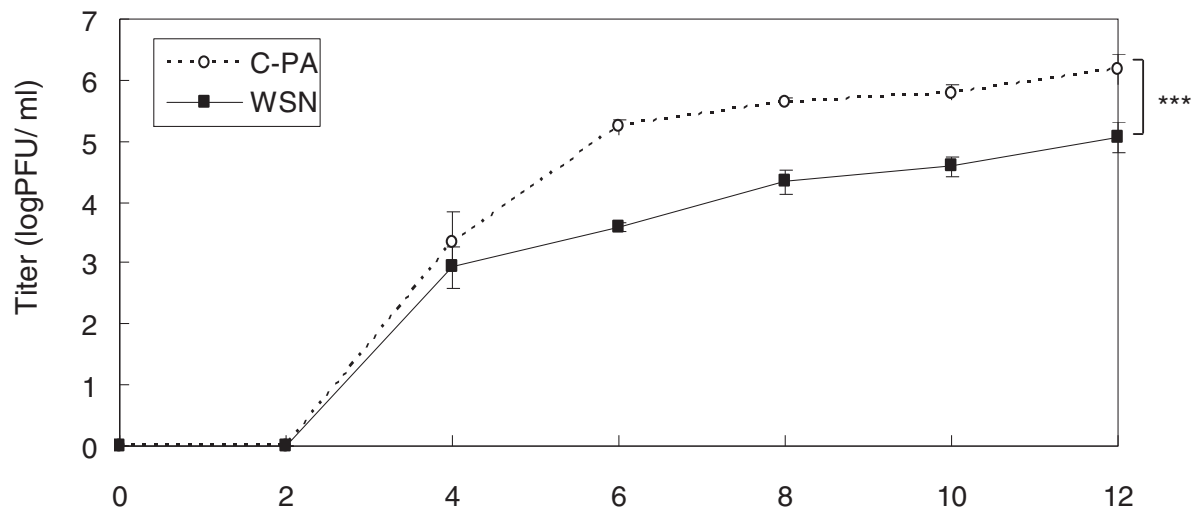

B

Time post infection (hr)

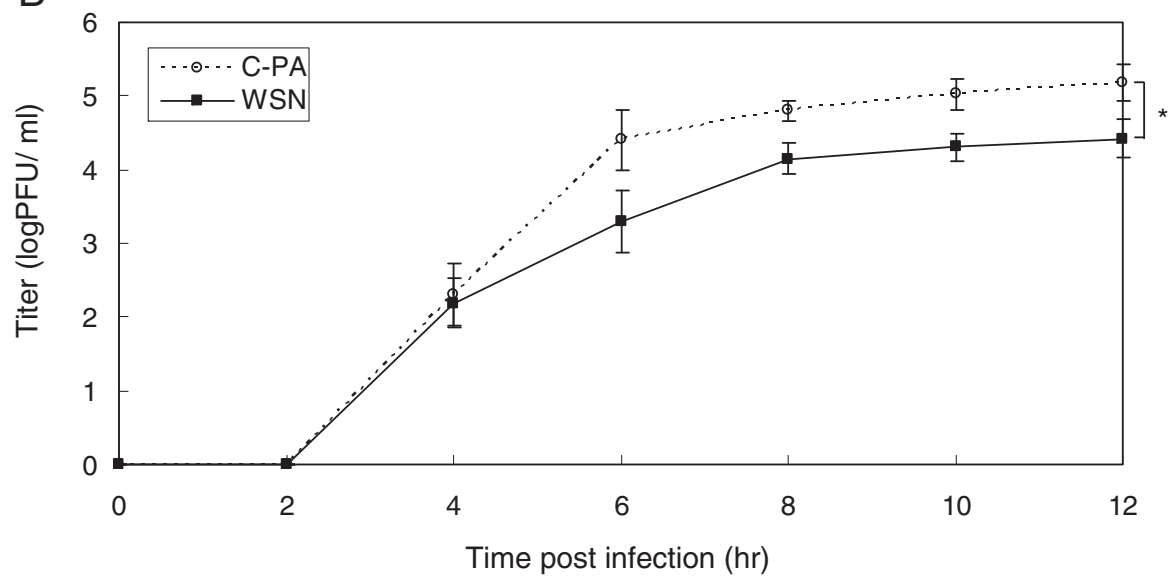

Figure 3 Single-step growth curves of C-PA and WSN in infected cells. MDCK (A) and Vero (B) cells were infected with C-PA or WSN at an $\mathrm{MOI}$ of 5. Viruses were harvested $2,4,6,8,10$, and $12 \mathrm{hr}$ after infection and their titers on MDCK cells measured by a plaque-formation assay. The mean and standard deviation (error bar in the graph) of each plaque titer were calculated from 3 independent experiments. Statistical significance was evaluated with Student's t-test. ${ }^{*} p<0.05,{ }^{* * *} p<0.005$. 


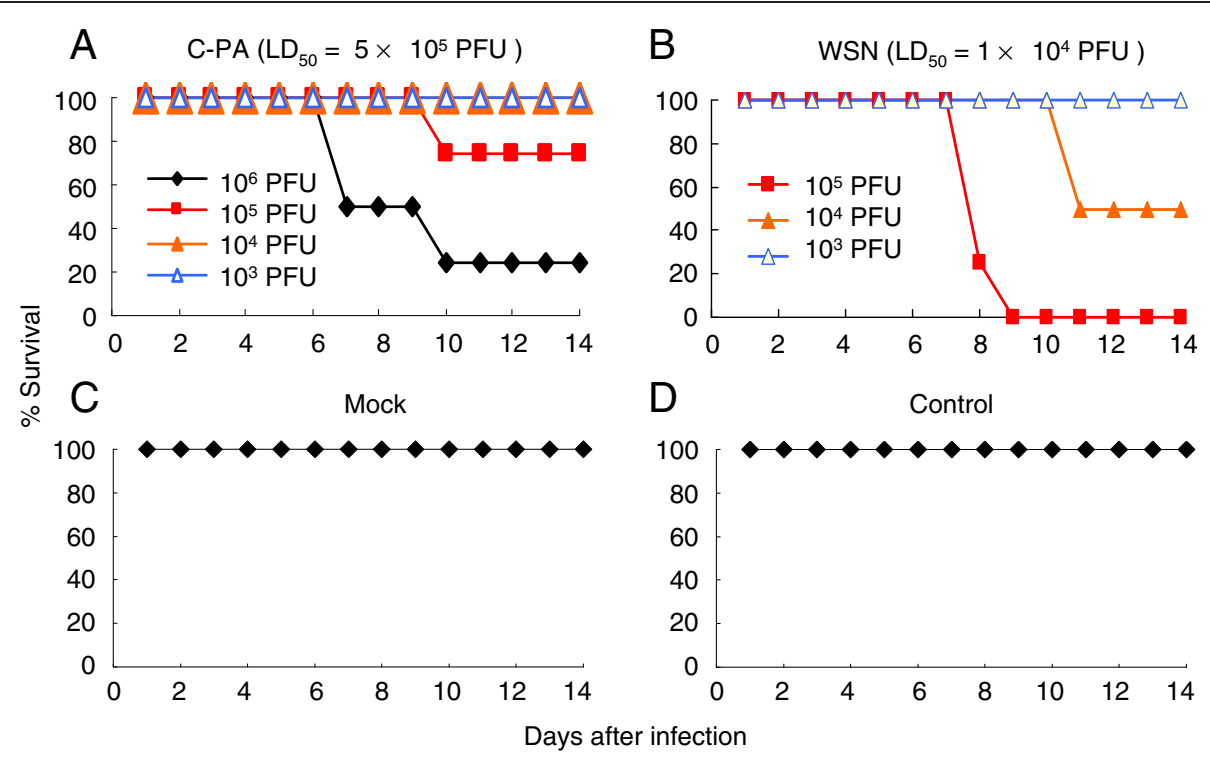

Figure 4 Survival curve of mice infected with C-PA or WSN. Groups of 4 mice were inoculated intra-nasally with $10^{6}, 10^{5}, 10^{4}$, or $10^{3}$ plaqueforming units (PFU) of C-PA (A) or 10 $0^{5}, 10^{4}$, or $10^{3}$ PFU of WSN (B) in a volume of $50 \mu \mathrm{L}$. The survival curves of the mock-infected (C) and nontreated (control) (D) mice are also shown. Survival status was monitored daily. $\mathrm{LD}_{50}$ is indicated above the graph (A and $B$ ).

on the activity of the host cellular defense system. First, we examined interferon $\beta$ induction in $293 \mathrm{~T}$ cells by measuring the activity of its promoter (Figure 5). A small amount of interferon $\beta$ was induced in cells infected with either C-PA or WSN 4 hr pi. However, interferon $\beta$ promoter activity was almost 3-fold higher $(\mathrm{p}<0.01)$ in the C-PA-infected cells than in the WSNinfected cells $8 \mathrm{hr}$ pi.

\section{TUNEL assay}

Next, we examined the induction of apoptosis in MDCK cells by performing TUNEL assays hourly from 8 to $16 \mathrm{hr}$ pi and once more $24 \mathrm{hr}$ pi. The numbers of

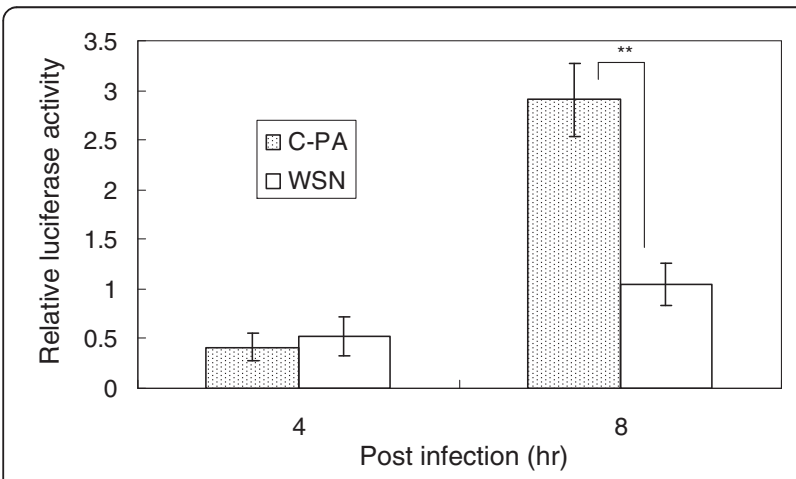

Figure 5 Interferon $\beta$ expression in C-PA- and WSN-infected cells. Interferon induction levels 4 and $8 \mathrm{hr}$ pi were measured as the luciferase activity from p-125Luc. The mean and standard deviation (error bar) of luciferase activity were calculated from 3 independent measurements. Statistical significance was evaluated with Student's $t$-test. ${ }^{* *} p<0.01$.
TUNEL-positive cells in 3 random fields were counted (Figure 6A). Before $11 \mathrm{hr}$ pi, we found fewer than 5 TUNEL-positive cells per field in either C-PA- or WSNinfected cells. Then, beginning $12 \mathrm{hr}$ pi, the numbers of the C-PA-infected TUNEL-positive cells increased to $20 \pm 3.5$ (12 hr), $27 \pm 2.5$ (13 hr), $41 \pm 4.0$ (14 hr), $46 \pm 2.6$ $(15 \mathrm{hr}), 48 \pm 2.6(16 \mathrm{hr})$, and $28 \pm 3.5(24 \mathrm{hr})$. The numbers of the WSN-infected TUNEL-positive cells remained less than 6 until $16 \mathrm{hr}$ and then increased to $40 \pm 4.6$ at $24 \mathrm{hr}$ pi. From 12 to $16 \mathrm{hr}$ pi, significantly more TUNEL-positive cells were observed among the C-PA-infected cells than among the WSN-infected cells $(p<0.005)$. TUNEL-positive cells were clearly observed among both C-PA- and WSN-infected cells, and significantly more TUNEL-positive cells were observed among WSN-infected cells than among C-PA-infected cells $24 \mathrm{hr}$ pi $(\mathrm{p}<0.05)$. In conclusion, TUNEL-positive cells appeared earlier in C-PA-infected cells than in WSNinfected cells. No differences in TUNEL staining were found among cells transfected with WSN and H5N1 Cambodia single-protein-expression plasmids (PB2, PB1, PA, HA, NP, NA, M1, M2, NS1, and NS2) or pcDNA3.1 (data not shown).

\section{Caspase 3, 8, and 9 activities}

TUNEL-positive cells may be apoptotic. Caspases are central players in both the intrinsic and the extrinsic pathways of apoptosis [44-46]. We therefore measured the activities of caspases 3, 8, and 9 in C-PA- and WSN-infected cells $10 \mathrm{hr}$ pi, $2 \mathrm{hr}$ before TUNEL-positive cells could first be observed among C-PA-infected cells, in order to confirm 


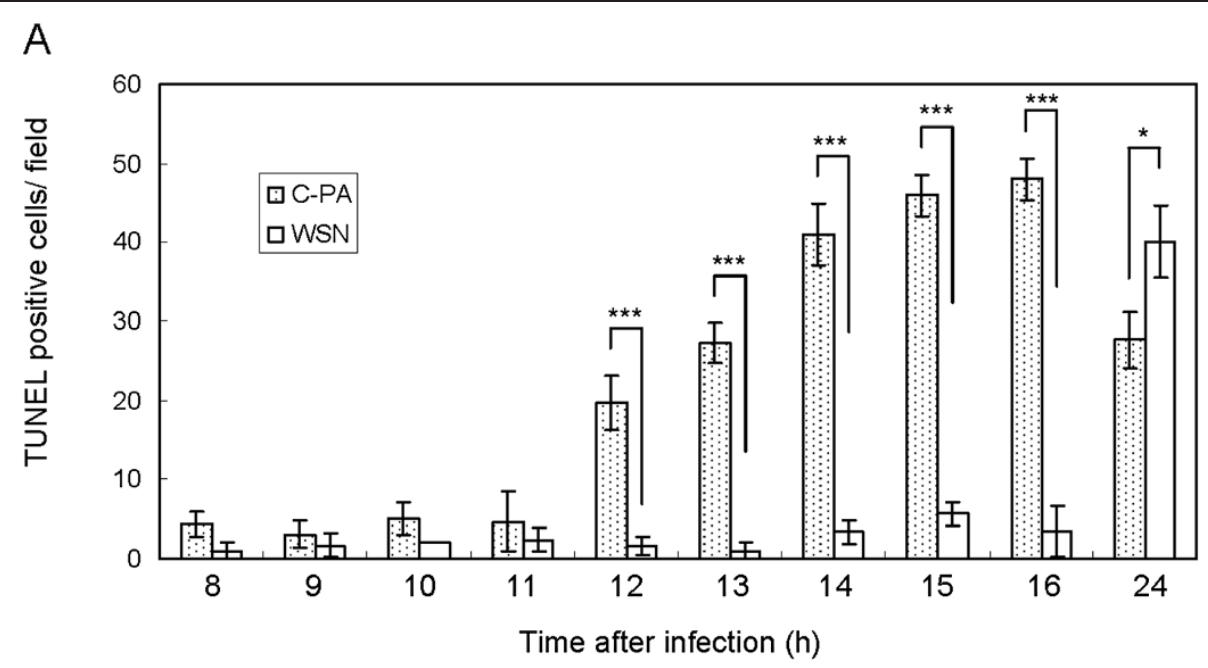

B

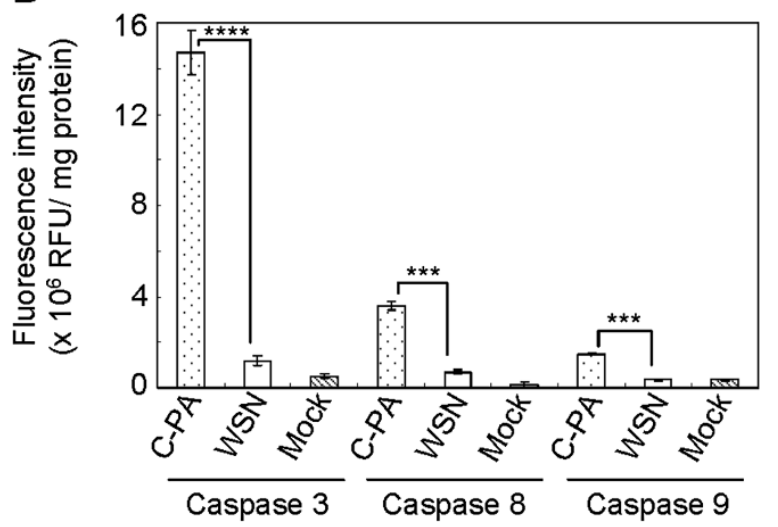

Figure 6 TUNEL staining and Caspase 3, 8, and 9 activities of C-PA- and WSN-infected cells. A. TUNEL assays were performed on C-PAand WSN-infected MDCK cells at the indicated time after infection. The mean and standard deviation (error bar) of the number of TUNEL-positive cells counted from 3 random fields were calculated. B. The activities of caspases 3, 8, and 9 in C-PA- and WSN-infected MDCK cells were measured $10 \mathrm{hr}$ pi. Caspase activity is expressed as the fluorescence intensity/total cellular protein $(\mathrm{mg})$ calculated from 3 independent measurements. Mock: mock-infected MDCK cells. Statistical significance was evaluated with Student's $t$-test. ${ }^{*} p<0.05,{ }^{* * *} p<0.005,{ }^{* * * *} p<0.0005$.

the induction of apoptosis (Figure 6B). The activities of caspases $3\left(14.7 \pm 9.8 \times 10^{6} \mathrm{RFU} / \mathrm{mg}\right.$ protein, $\left.\mathrm{p}<0.0005\right)$, $8\left(3.6 \pm 0.2 \times 10^{6} \mathrm{RFU} / \mathrm{mg}\right.$ protein, $\left.\mathrm{p}<0.005\right)$, and 9 $\left(1.5 \pm 0.5 \times 10^{6} \mathrm{RFU} / \mathrm{mg}\right.$ protein, $\left.\mathrm{p}<0.005\right)$ were higher in C-PA-infected cells than in WSN-infected cells $10 \mathrm{hr}$ pi (comparisons evaluated by Student's $t$ test). The caspase activities in WSN-infected cells were similar to those in mock-infected cells, indicating that WSN infection did not induce apoptosis $10 \mathrm{hr}$ pi. The activation of caspase 9 in C-PA-infected cells indicates that C-PA infection induces apoptosis through the mitochondrial pathway [47-49], and the apoptosis induction by C-PA began at an early time after infection at which no apoptosis was induced by WSN infection.

\section{Histopathology and TUNEL assay of infected mice}

Finally, we compared the pathological changes in the lung between C-PA- and WSN-infected mice. The histopathological appearances were similar (Figure 7). The major difference between C-PA- and WSN-infected lungs is that pulmonary edema around blood vessels was present in the C-PA-infected lungs from day $1 \mathrm{pi}$, although it was also present in WSN-infected lungs on days 3 and 4 pi. On the first day of infection, a moderate amount of lymphocyte infiltration was observed around the bronchioles of C-PA-infected mouse lungs, and this inflammation decreased on days 3 and 4. More lymphocyte infiltration around the bronchioles was observed in WSN-infected mouse lungs on days $1-3$, with the most severe inflammation on day 2 , and only mild inflammation was observed on day 4. No pathological change was observed in the mock-infected or non-infected mouse lungs.

We simultaneously analyzed these samples by TUNEL assay. A few TUNEL-positive cells were observed in both C-PA- and WSN-infected mouse lungs on days 1-4 pi, 


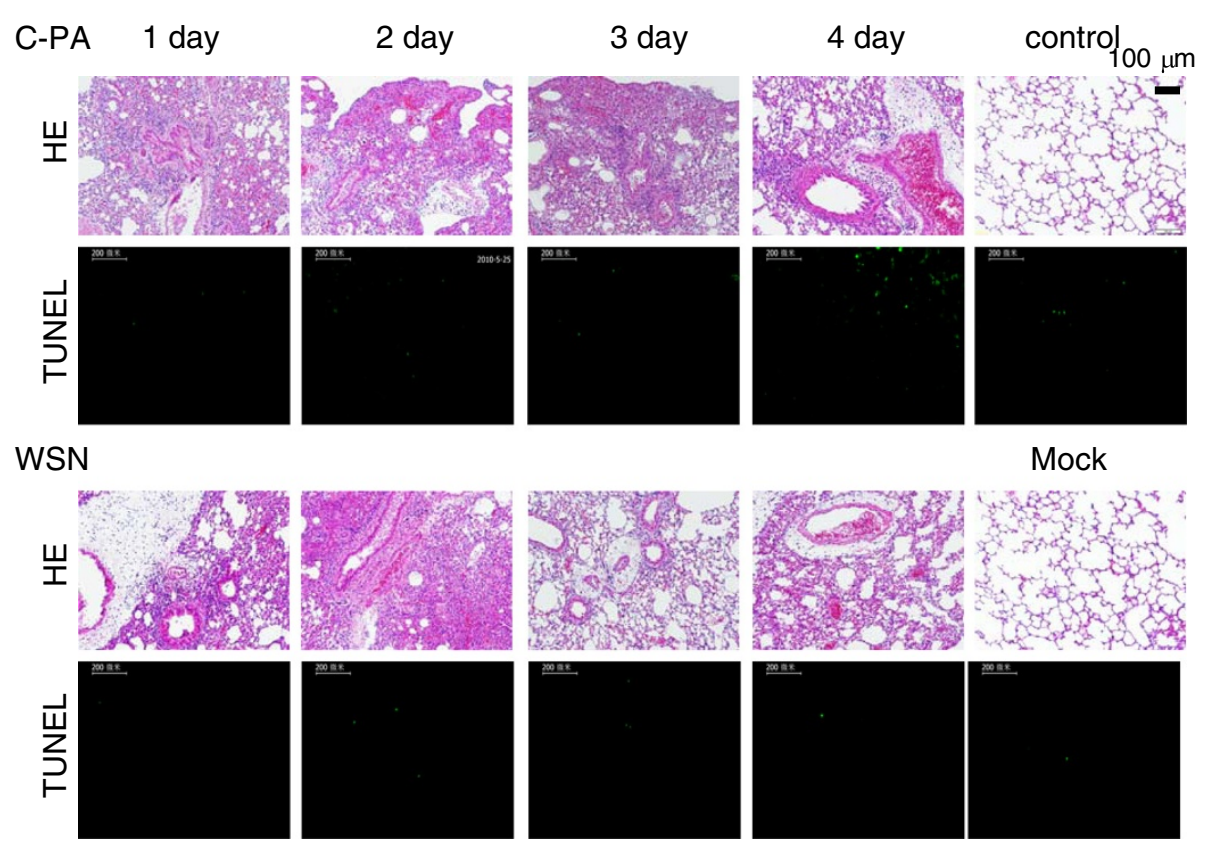

Figure 7 Histopathology of C-PA- and WSN-infected mouse lungs. The lungs of mice infected with C-PA or WSN (10 $\mathrm{PFU} / \mathrm{mouse})$ at the indicated days after infection were imaged after hematoxylin and eosin (HE) or TUNEL staining. Control: non-infected mouse lung. The bar above the picture indicates $100 \mu \mathrm{m}$ and the bars in the fluorescence microgram indicate $200 \mu \mathrm{m}$.

but the numbers did not clearly differ between the 2 viruses. The histopathological findings indicated recovery of the C-PA-infected mouse lungs, which is consistent with the lower pathogenicity of C-PA.

\section{Discussion}

The activation of replicon activity by H5N1 HPAIV PA observed in this study has been reported several times (Figure 1) [34,50,51]. Influenza viruses with high polymerase activity have been reported to show high pathogenicity $[7,8]$. Therefore, reassortment of H5N1 HPAIV PA into human influenza viruses, including the seasonal influenza viruses ( $\mathrm{H} 1 \mathrm{~N} 1$ and $\mathrm{H} 3 \mathrm{~N} 2)$ and the pandemic influenza virus (H1N1), is a serious concern [34], although this event may not occur easily [32]. The major factor for host adaptation in H5N1 HPAIV RNP is PB2, which shows a strong correlation with pathogenicity in mammalian hosts, including humans [30,31,51-55].

The WSN reconstitution system [56] was used to analyze the effect of H5N1 Cambodia PA in an animal influenza virus (H1N1). Contrary to our expectation, the multi-step growth of C-PA in MDCK and CEF cells was less than that of WSN, and its pathogenicity was low because of this attenuation (Figures 2, 4). We confirmed the absence of mutations in the C-PA genome. As we previously found a similar discrepancy in influenza promoter/origin function due to a difference in activation of the host defense system [42], we examined whether the discrepancy between $\mathrm{RdRp}$ activity and pathogenicity was also due to differences in host defense. As the multi-step growth of C-PA in Vero cells was better than that of WSN, and because its single-step growth, which is highly dependent on the polymerase activity, in both MDCK and Vero cells was better than that of WSN (Figure 3), we first examined the activity of the interferon $\beta$ promoter and found that it was strongly activated (Figure 5) in CPA-infected cells.

Type I interferon is induced in virus-infected cells by a signal transduction pathway beginning with retinoicacid-inducible gene-I (RIG-I), which recognizes 5'triphosphate-containing influenza RNA [57-62]. In CPA-infected cells, a large amount of vRNA was expressed from early stages of infection, which might more strongly trigger interferon induction (Figures 5 and Additional file: Figure S3) and thereby induce an antiviral state in uninfected cells that protected them from influenza infection (Additional file: Figure S2A) [63-65]. The better multi-step growth of C-PA relative to WSN in Vero cells, which are defective in type-I interferon production [66] (Figure 2C), and the better single-step growth of C-PA than of WSN (Figure 3), are consistent with the high in vitro polymerase activity and strong interferon induction in C-PA infected cells.

Apoptosis (programmed cell death) is another mechanism by which cells restrict viral infection including influenza [67]. However, virus-induced apoptosis causes tissue damage, which is one of the mechanisms of influenza pathogenicity [68]. Apoptosis also aids in the 
release of influenza viruses [69,70]. WSN induced apoptosis in MDCK cells late in infection [71]. However, no apoptosis was induced by expression of any single protein of either WSN or H5N1 Cambodia. Apoptosis was strongly induced in C-PA-infected cells beginning early in infection when no apoptosis was induced in WSNinfected cells (Figure 6). The activation of caspase 9 indicated that this apoptosis was mediated through the mitochondrial pathway [72]. The increased expression of vRNA (Additional file: Figure S3) in C-PA infected cells due to the high replication activity promoted by H5N1 PA (Figure 1) induced both interferon and apoptosis, resulting in attenuation of C-PA proliferation (Figure 2). Neither caspase 3 nor 8 was induced by expression of WSN PA or Cambodia PA alone (data not shown). The strong induction of interferon discussed above also stimulates the induction of apoptosis via RNA-dependent protein kinase (PKR) [73]. Such rapid induction of apoptosis was also observed in duck cells infected with HPAIV [68]. However, in case of C-PA, early induction of apoptosis attenuated the proliferation of the virus and thus decreased its pathogenicity.

PB1-F2 is the only influenza virus protein that induces apoptosis in infected monocytes and potentiates apoptosis during infection [74-76]. The WSN PB1-F2 proteins of WSN and C-PA are identical. Kinetic analysis of viral RNAs (Additional file: Figure S3) indicates that PB1-F2 is unlikely to contribute to the strong induction of apoptosis in C-PA infected cells.

C-PA infection strongly induced both interferon production and apoptosis early in infection, which attenuated virus proliferation and pathogenicity despite high $\mathrm{RdRp}$ activity. This may be another reason, in addition to poor adaptation, for the difficulty of obtaining reassortant viruses carrying H5N1 HPAIV PA [31,32].

\section{Methods}

\section{Cell culture}

$293 \mathrm{~T}$ and Vero cells were maintained in Dulbecco's modified Eagle minimal essential medium (DMEM) containing 10\% fetal bovine serum (FBS). CEFs were prepared from 11-day-old embryonated chicken eggs by trypsin digestion and stored in liquid nitrogen. CEF and MDCK cells were maintained in DMEM containing 10\% or $5 \%$ FBS, respectively.

\section{Replicon assay}

A standard replicon assay was performed as previously described [41,42,77]. Luciferase activity was measured using the Dual-Glo luciferase assay kit and a GloMax 96 Microplate Luminometer (Promega, Fitchburg, USA) after transfection of $0.1 \mu \mathrm{g}$ each of pCPB2, pCPB1, pCPA, pCNP, and ppolINSluc and $0.01 \mu \mathrm{g}$ of $\mathrm{pRL}_{\mathrm{SV} 40}$ (Promega) using Lipofectamine 2000 (Invitrogen,
Carlsbad, USA). The PB2, PB1, PA, and NP genes of influenza A/Cambodia/P096/2005 (H5N1) [40] and A/WSN/ 33 (H1N1) [56] were PCR-amplified using specific oligonucleotides and cloned into pcDNA3.1(+) (Invitrogen), resulting in pcCamPB2wt, pcCamPB1, pcCamPA, pcCamNP, pcWSNPB2, pcWSNPB1, pcWSNPA, and pcWSNNP, respectively. Only data in which the variation of the Renilla luciferase activity was less than 3-fold variations were used. The oligonucleotide sequence information will be made available upon request.

\section{Expression, purification, and in vitro transcription of the influenza virus RdRp}

Expression, purification, and in vitro transcription of the influenza virus $\mathrm{RdRp}$ were performed as previously described [42,77,78]. Briefly, $100 \mathrm{nM}$ influenza RdRp was incubated in $50 \mathrm{mM}$ Tris- $\mathrm{HCl}(\mathrm{pH} 8.0), 8 \mathrm{mM}$ $\mathrm{MgCl}_{2}, 150 \mathrm{mM} \mathrm{NaCl}, 2 \mathrm{mM}$ DTT, $0.5 \mathrm{mM}$ ATP, $0.5 \mathrm{mM}$ CTP, $0.5 \mathrm{mM}$ GTP, $0.05 \mathrm{mM}\left[\alpha{ }^{32} \mathrm{P}\right] \mathrm{UTP}$, $0.1 \mathrm{mM}$ ApG or $0.01 \mathrm{mg} / \mathrm{mL}$ globin mRNA, $2000 \mathrm{U} / \mathrm{mL}$ RNase inhibitor, and $200 \mathrm{nM}$ v84 and c84 model template RNA at $25{ }^{\circ} \mathrm{C}$ for $90 \mathrm{~min}$. The product was analyzed by PAGE on $6 \%$ gels containing $8 \mathrm{M}$ urea and the images analyzed with a Typhoon Trio plus (GE Healthcare, Bucks, UK).

\section{Model RNA templates}

v84 and c84 model RNA templates were prepared as previously reported [11].

\section{Western blotting}

Proteins were blotted onto nitrocellulose membranes (Millipore, Billerica, USA) by semi-dry electroblotting (Bio-Rad, Hercules, USA) after SDS-PAGE on 10\% gels. The blotted membranes were blocked with $10 \%$ skim milk in $20 \mathrm{mM}$ Tris- $\mathrm{HCl}$ (pH 7.5), $150 \mathrm{mM} \mathrm{NaCl}$, and $0.02 \%$ Tween 20 (TBST), and western blotting was performed using rabbit anti-PB1, -PB2, -PA [11], and -PR8 (1:1,000 each) and anti-actin (1:100) antibodies as the primary antibodies. The membranes were then incubated with alkaline phosphatase-conjugated anti-rabbit IgG $(1: 7,500)$ or anti-mouse IgG $(1: 7,500)$, and the positions of the bound antibodies were visualized with nitroblue tetrazolium (NBT) and 5-bromo-4-chloro-3-indolyl phosphate (BCIP).

\section{Reconstitution of influenza virus and plaque-formation assay} pHH21 and the influenza virus 12-plasmid reconstitution system of WSN were kindly provided by Dr. Hobom and Dr. Kawaoka [56]. The H5N1 A/Cambodia/ P0322095/2005 [40] PA sequence was inserted into ppolI-WSN-PA, resulting in ppolI-Cam-PA. The influenza virus WSN strain (WSN) and WSN carrying H5N1 
Cambodia PA (C-PA) were reconstituted by co-transfection of $293 \mathrm{~T}$ cells with ppolI-WSN-PB2, ppolI-WSN-PB1, ppolI-WSN-PA or ppolI-Cam-PA, ppolI-WSN-HA, ppolIWSN-NP, ppolI-WSN-NA, ppolI-WSN-M, and ppolIWSN-NS with pCPB2, pCPB1, pCPA, and pCNP $[10,56]$ using Lipofectamine 2000. The reconstituted viruses were recovered from the culture media $72 \mathrm{hr}$ posttransfection. The viruses were plaque-purified, amplified, and titered on MDCK cells by a plaque-formation assay and stored at $-80{ }^{\circ} \mathrm{C}$. The genome sequences of all viruses were determined by RT-PCR. The primer sequences used will be made available upon request.

\section{Virus growth assay}

MDCK, CEF, and Vero cells in 3.5-cm dishes (21 dishes of MDCK cells and CEFs, 27 dishes of Vero cells per a virus) were infected with WSN and C-PA at an MOI of 0.01 at $37{ }^{\circ} \mathrm{C}$ for $1 \mathrm{hr}$ (multi-step growth assay). The cells were washed $3 \times$ with phosphate-buffered saline (PBS) and incubated with $2 \mathrm{~mL}$ of DMEM containing $2 \%$ FBS (without trypsin) at $37{ }^{\circ} \mathrm{C}$, as WSN replicates without trypsin [79]. All of the supernatants of 3 dishes of each cell were taken $6,12,24,36,48$, and $60 \mathrm{hr}$ (and also at 72 and $90 \mathrm{hr}$ for Vero cells) after infection and stored at $-80{ }^{\circ} \mathrm{C}$. Virus growth was also tested in MDCK and Vero cells after infection at an MOI of 5 (single-step growth assay). Supernatants were harvested 2, 4, 6, 8, 10, and $12 \mathrm{hr}$ after infection. The viruses in the supernatants were titered on MDCK cells by a plaque-formation assay.

\section{Mouse infection}

Groups of 4 6-week-old female BALB/c mice (Sino-British Laboratory Animal, Shanghai, China) were anesthetized with ether and inoculated with $10^{5}, 10^{4}$, or $10^{3}$ PFU of WSN or $10^{6}, 10^{5}, 10^{4}$, or $10^{3}$ PFU of C-PA in a volume of $50 \mu \mathrm{L}$ by nasal dropping. Four mice were inoculated with $50 \mu \mathrm{L}$ of PBS as a mock-infection control. The survival rates were monitored daily and the $50 \%$ lethal doses $\left(\mathrm{LD}_{50} \mathrm{~s}\right)$ calculated [41].

\section{Histopathological analysis}

Six-week-old female BALB/c mice were anesthetized with ether and inoculated with $10^{5} \mathrm{PFU}$ of WSN or C-PA in $50 \mu \mathrm{L}$ by nasal dropping. Mice were inoculated with $50 \mu \mathrm{L}$ of PBS as a mock-infection control. A non-treated mouse was used as a non-treated control. The mockinfected and infected mice were sacrificed by cervical dislocation under anesthesia on days $1,2,3$, and 4 after infection, and their lungs were removed and fixed with $3.5 \%$ formalin/PBS at $25^{\circ} \mathrm{C}$ for 2 days. The lungs were embedded in paraffin blocks, sectioned at 4- $\mu \mathrm{m}$ thickness, and stained with hematoxylin and eosin (HE).

\section{TUNEL assay}

Cells were placed on cover slips in 24-well plates and infected with WSN or C-PA at an MOI of 0.01. Eight, 9, $10,11,12,13,14,15,16$, and $24 \mathrm{hr}$ after infection, cells were fixed with $1 \%$ formalin/PBS. The TUNEL assay was performed using the DeadEnd ${ }^{\mathrm{TM}}$ Fluorometric TUNEL system according to the company's instructions. The samples were observed using a fluorescence microscope (Leica DM IRB, Leica, Wetzlar, Germany), and the numbers of TUNEL positive cells in 3 random fields were counted.

\section{Caspase activity}

MDCK cells were plated in 10-cm-diameter plates and infected with WSN or C-PA at an MOI of 0.01. $10 \mathrm{hr}$ after infection, the cells were harvested and the activities of caspases 3, 8, and 9 measured using the Caspase-3/ CPP32 Fluorometric Assay kit, the Caspase 8/FLICE Fluorometric Assay kit, and the Caspase 9 Fluorometric Assay kit (Biovision, Inc., Milpitas, USA) according to the manufacturer's instructions.

\section{Interferon induction}

Interferon induction was analyzed by measuring the luciferase activity of cells transfected with p-125Luc, which was kindly provided by Dr. Fujita [80]. $293 \mathrm{~T}$ cells were transfected with $\mathrm{p}$-125Luc $(1 \mu \mathrm{g})$ and $\mathrm{pRL}_{\mathrm{SV} 40}(100 \mathrm{ng})$. Four hours post-transfection, the cells were infected with WSN or C-PA at an MOI of 0.01 . The interferon promoter activity was measured as the luciferase activity using the Dual-Glo luciferase assay kit and a GloMax 96 Microplate Luminometer (Promega) and normalized as the firefly luciferase/Renilla luciferase activity ratio.

\section{Chemicals and radioisotopes}

Non-radiolabeled nucleotides were purchased from GE Healthcare, $\left[\alpha-{ }^{32}\right.$ P]UTP from New England Nuclear (PerkinElmer Life Sciences, Waltham, USA), and T7 RNA polymerase, T4 nucleotide kinase, oligonucleotides, human placental RNase inhibitor, and restriction enzymes from Takara (Dalian, China). The RPAIII Ribonuclease Protection Assay Kit was purchased from Ambion (Austin, USA). Anti-actin antibodies were purchased from Sigma Aldrich (St. Louis, USA). The Dual-Glo luciferase assay kit, DeadEnd ${ }^{\mathrm{TM}}$ Fluorometric TUNEL system, alkaline phosphatase-conjugated anti-rabbit and anti-mouse IgG's, NBT, and BCIP were purchased from Promega. DMEM, FBS, Lipofectamine 2000, and Trizol reagent were purchased from Invitrogen.

\section{Statistical analysis}

The statistical significance levels of the data were evaluated by Student's $t$-test, with $\mathrm{p}<0.05$ indicating statistical significance. 


\section{Additional file}

Additional file 1: Results, Methods. Figure S1. Expression of RdRp subunits and NP in the transfected cells. Figure S2. Time course of NP protein expression by C-PA and WSN. Figure S3. Time courses of NP VRNA, CRNA, and mRNA expression by C-PA and WSN.

\section{Competing Interests}

The authors declare that they have no competing interests.

\section{Author's contributions}

QW, SZ, HJ, JW, LW, YM, and KX carried out the experiments. SS, FY, and MK analyzed caspase activity and mouse lung tissues. PB and VD isolated and cloned HPAIV H5N1 Cambodia. QW, SZ, SB, and TT conceived of the study. QW and SZ analyzed the data and drafted the manuscript, and SB and TT reviewed the manuscript. All authors read and approved the final manuscript.

\section{Acknowledgements}

We thank Drs. T. Fujita, G. Hobom, and Y. Kawaoka for p-125Luc, pHH21, and the influenza virus 12-plasmid reconstitution system, respectively. This work was supported by Grants-in-aid from the Chinese Academy of Sciences (0514P51131), the National Science Foundation of China (30970153), the Li Ka Shing Foundation (0682P11131), RESPARI (0581P14131), and European Union (FLUINNATE 0681P21131).

\section{Author details}

${ }^{1}$ Units of Molecular Virology, the Key Laboratory of Molecular Virology \& Immunology, Institut Pasteur of Shanghai, Chinese Academy of Sciences, 411 Hefei Road, 200025, Shanghai, P. R. China. ${ }^{2}$ Units of Viral Genome Regulation, the Key Laboratory of Molecular Virology \& Immunology, Institut Pasteur of Shanghai, Chinese Academy of Sciences, 411 Hefei Road, 200025, Shanghai, P. R. China. ${ }^{3}$ Shanghai Medical College of Fudan University, Yixueyuan Road 138, Shanghai 200032, P. R. China. ${ }^{4}$ Roche R\&D Center China LTD, 720 Cai Lun Road, Building 5, Pudong, Shanghai 201203, P. R. China. ${ }^{5}$ Department of Microbiology and Cell Biology, Tokyo Metropolitan Institute of Medical Biology, 3-18-22 Honkomagome, Bunkyo-Ku, Tokyo 113-8613, Japan. ' Institut Pasteur in Cambodia, 5 Monivong Blvd, P.O. Box 983, Phnom Penh, Cambodia. ${ }^{7}$ Choju Medical Institute, Fukushimura Hospital, 19-14 Azanakayama, Noyori-cho, Toyohashi, Aichi 441-8124, Japan.

Received: 14 October 2011 Accepted: 21 May 2012

Published: 8 June 2012

\section{References}

1. Webster RG, Sharp GB, Claas EC: Interspecies transmission of influenza viruses. Am J Respir Crit Care Med 1995, 152:S25-30.

2. Kawaoka Y, Krauss S, Webster RG: Avian-to-human transmission of the PB1 gene of influenza A viruses in the 1957 and 1968 pandemics. J Virol 1989, 63:4603-4608

3. Lindstrom SE, Cox NJ, Klimov A: Genetic analysis of human H2N2 and early H3N2 influenza viruses, 1957-1972: evidence for genetic divergence and multiple reassortment events. Virology 2004, 328:101-119.

4. Dawood FS, Jain S, Finelli L, Shaw MW, Lindstrom S, Garten RJ, Gubareva LV, $\mathrm{Xu} X$, Bridges CB, Uyeki TM: Emergence of a novel swine-origin influenza A (H1N1) virus in humans. N Engl J Med 2009, 360:2605-2615.

5. Wasilenko JL, Lee CW, Sarmento L, Spackman E, Kapczynski DR, Suarez DL, Pantin-Jackwood MJ: NP, PB1, and PB2 viral genes contribute to altered replication of H5N1 avian influenza viruses in chickens. J Virol 2008, 82:4544-4553.

6. Hulse-Post DJ, Franks J, Boyd K, Salomon R, Hoffmann E, Yen HL, Webby RJ, Walker D, Nguyen TD, Webster RG: Molecular changes in the polymerase genes (PA and PB1) associated with high pathogenicity of H5N1 influenza virus in mallard ducks. J Virol 2007, 81:8515-8524.

7. Seyer R, Hrincius ER, Ritzel D, Abt M, Mellmann A, Marjuki H, Kuhn J, Wolff T, Ludwig S, Ehrhardt C: Synergistic adaptive mutations in the hemagglutinin and polymerase acidic protein lead to increased virulence of pandemic $2009 \mathrm{H} 1 \mathrm{~N} 1$ influenza A virus in mice. J Infect Dis 2012, 205:262-271.
8. Salomon R, Franks J, Govorkova EA, Ilyushina NA, Yen HL, Hulse-Post DJ, Humberd J, Trichet M, Rehg JE, Webby RJ, et al: The polymerase complex genes contribute to the high virulence of the human H5N1 influenza virus isolate A/Vietnam/1203/04. J Exp Med 2006, 203:689-697.

9. Palese P, Shaw ML: Orthomyxoviridae: The Viruses and Their Replication In Fields Virology. 5th edition. Edited by Knipe DM, Howley PM. Philadelphia: Lippincott Williams \& Wilkins; 2007:1647-1689.

10. Toyoda T, Adyshev DM, Kobayashi M, Iwata A, Ishihama A: Molecular assembly of the influenza virus RNA polymerase: determination of the subunit-subunit contact sites. J Gen Virol 1996, 77(Pt 9):2149-2157.

11. Kobayashi M, Toyoda T, Ishihama A: Influenza virus PB1 protein is the minimal and essential subunit of RNA polymerase. Arch Virol 1996, 141:525-539.

12. Biswas SK, Nayak DP: Mutational analysis of the conserved motifs of influenza A virus polymerase basic protein 1. J Virol 1994, 68:1819-1826.

13. Ulmanen I, Broni BA, Krug RM: Role of two of the influenza virus core $\mathbf{P}$ proteins in recognizing cap 1 structures ( $\mathrm{m} 7 \mathrm{G}$ pppNm) on RNAs and in initiating viral RNA transcription. Proc Natl Acad Sci U S A 1981, 78:73557359 .

14. Li ML, Rao P, Krug RM: The active sites of the influenza cap-dependent endonuclease are on different polymerase subunits. EMBO J 2001 20:2078-2086.

15. Blaas $D$, Patzelt $E$, Kuechler $E$ : Cap-recognizing protein of influenza virus. Virology 1982, 116:339-348.

16. Crepin T, Dias A, Palencia A, Swale C, Cusack S, Ruigrok RW: Mutational and metal binding analysis of the endonuclease domain of the influenza virus polymerase PA subunit. J Virol 2010, 84:9096-9104.

17. Dias A, Bouvier D, Crepin T, McCarthy AA, Hart DJ, Baudin F, Cusack S, Ruigrok RW: The cap-snatching endonuclease of influenza virus polymerase resides in the PA subunit. Nature 2009, 458:914-918.

18. Fodor $\mathrm{E}$, Brownlee $\mathrm{G}$ : Influenza virus replication. In Influenza. Edited by Potter C. Amsterdom: Elsevier; 2002:1-29.

19. Hara K, Schmidt Fl, Crow M, Brownlee GG: Amino acid residues in the Nterminal region of the PA subunit of influenza A virus RNA polymerase play a critical role in protein stability, endonuclease activity, cap binding, and virion RNA promoter binding. J Virol 2006, 80:7789-7798.

20. Yuan P, Bartlam M, Lou Z, Chen S, Zhou J, He X, Lv Z, Ge R, Li X, Deng T, et al: Crystal structure of an avian influenza polymerase $\mathrm{PA}(\mathrm{N})$ reveals an endonuclease active site. Nature 2009, 458:909-913.

21. Kawakami K, Mizumoto K, Ishihama A: RNA polymerase of influenza virus. IV. Catalytic properties of the capped RNA endonuclease associated with the RNA polymerase. Nucleic Acids Res 1983, 11:3637-3649.

22. Plotch SJ, Bouloy M, Ulmanen I, Krug RM: A unique cap(m7G pppXm)dependent influenza virion endonuclease cleaves capped RNAs to generate the primers that initiate viral RNA transcription. Cell 1981, 23:847-858.

23. Krug RM, Alonso-Caplan FV, Julkunen I, Katze MG: Expression and replication of the influenza virus genome. In Edited by Krug RM. New York: Plenum Press; 1989:89-152.

24. Deng T, Vreede FT, Brownlee GG: Different de novo initiation strategies are used by influenza virus RNA polymerase on its CRNA and viral RNA promoters during viral RNA replication. J Virol 2006, 80:2337-2348,

25. Zhang S, Wang J, Wang Q, Toyoda T: Internal initiation of influenza virus replication of $\mathrm{v}$ - and CRNA in vitro. J Biol Chem 2010, 285:41194-41201.

26. Neumann G, Shinya K, Kawaoka Y: Molecular pathogenesis of H5N1 influenza virus infections. Antivir Ther 2007, 12:617-626.

27. Abdel-Ghafar AN, Chotpitayasunondh T, Gao Z, Hayden FG, Nguyen DH, de Jong MD, Naghdaliyev A, Peiris JS, Shindo N, Soeroso S, Uyeki TM: Update on avian influenza $\mathrm{A}(\mathrm{H} 5 \mathrm{~N} 1)$ virus infection in humans. $N$ Engl J Med 2008, 358:261-273.

28. Uyeki TM: Global epidemiology of human infections with highly pathogenic avian influenza A (H5N1) viruses. Respirology 2008, 13 (Suppl 1):S2-9.

29. Maines TR, Chen LM, Matsuoka Y, Chen H, Rowe T, Ortin J, Falcon A Nguyen $\mathrm{TH}$, le Mai Q, Sedyaningsih ER, et al: Lack of transmission of H5N1 avian-human reassortant influenza viruses in a ferret model. Proc Nat Acad Sci U S A 2006, 103:12121-12126.

30. Li C, Hatta M, Watanabe S, Neumann G, Kawaoka Y: Compatibility among polymerase subunit proteins is a restricting factor in reassortment between equine H7N7 and human H3N2 influenza viruses. J Virol 2008, 82:11880-11888. 
31. Chen LM, Davis CT, Zhou H, Cox NJ, Donis RO: Genetic compatibility and virulence of reassortants derived from contemporary avian $\mathrm{H} 5 \mathrm{~N} 1$ and human H3N2 influenza A viruses. PLoS Pathog 2008, 4:e1000072.

32. Hatta M, Halfmann P, Wells K, Kawaoka Y: Human influenza a viral genes responsible for the restriction of its replication in duck intestine. Virology 2002, 295:250-255.

33. Gutiérrez R, Naughtin M, Horm S, San S, Buchy P: A(H5N1) Virus Evolution in South East Asia. Viruses 2009, 1:335-361.

34. Kashiwagi T, Leung BW, Deng T, Chen H, Brownlee GG: The N-terminal region of the PA subunit of the RNA polymerase of influenza A/HongKong/156/97 (H5N1) influences promoter binding. PLoS One 2009, 4:e5473.

35. Fodor $E$, Crow M, Mingay LJ, Deng T, Sharps J, Fechter P, Brownlee GG: A single amino acid mutation in the PA subunit of the influenza virus RNA polymerase inhibits endonucleolytic cleavage of capped RNAs. J Virol 2002, 76:8989-9001.

36. Hara K, Shiota M, Kido H, Ohtsu Y, Kashiwagi T, Iwahashi J, Hamada N, Mizoue K, Tsumura N, Kato H, Toyoda T: Influenza virus RNA polymerase PA subunit is a novel serine protease with Ser624 at the active site. Genes Cells 2001, 6:87-97.

37. Sanz-Ezquerro JJ, Zurcher T, de la Luna S, Ortin J, Nieto A: The aminoterminal one-third of the influenza virus PA protein is responsible for the induction of proteolysis. J Virol 1996, 70:1905-1911.

38. Song MS, Pascua PN, Lee JH, Baek YH, Lee OJ, Kim CJ, Kim H, Webby RJ, Webster RG, Choi YK: The polymerase acidic protein gene of influenza a virus contributes to pathogenicity in a mouse model. J Virol 2009, 83:12325-12335.

39. Kashiwagi T, Hara K, Nakazono Y, Hamada N, Watanabe H: Artificial hybrids of influenza A virus RNA polymerase reveal PA subunit modulates its thermal sensitivity. PLoS One 2010, 5:e15140.

40. Buchy P, Mardy S, Vong S, Toyoda T, Aubin JT, Miller M, Touch S, Sovann L, Dufourcq JB, Richner B, et al: Influenza A/H5N1 virus infection in humans in Cambodia. J Clin Virol 2007, 39:164-168.

41. Toyoda T, Hara K, Imamura Y: Ser624 of the PA subunit of influenza A virus is not essential for viral growth in cells and mice, but required for the maximal viral growth. Arch Virol 2003, 148:1687-1696.

42. Jiang H, Zhang S, Wang Q, Wang J, Geng L, Toyoda T: Influenza virus genome C4 promoter/origin attenuates its transcription and replication activity by the low polymerase recognition activity. Virology 2010, 408:190-196.

43. Reed $\sqcup$, Muench $H$ : Simple method of estimating 50 per cent endpoinds. Amer J Hyg 1938, 27:493-497.

44. Wang C, Youle RJ: The role of mitochondria in apoptosis*. Annu Rev Genet 2009, 43:95-118.

45. Li J, Yuan J: Caspases in apoptosis and beyond. Oncogene 2008, 27:61946206.

46. Roulston A, Marcellus RC, Branton PE: Viruses and apoptosis. Annu Rev Microbiol 1999, 53:577-628.

47. Desagher S, Martinou JC: Mitochondria as the central control point of apoptosis. Trends Cell Biol 2000, 10:369-377.

48. Kroemer $\mathrm{G}$ : The proto-oncogene $\mathrm{BCl}-2$ and its role in regulating apoptosis. Nat Med 1997, 3:614-620.

49. Kroemer G: Mitochondrial implication in apoptosis. Towards an endosymbiont hypothesis of apoptosis evolution. Cell Death Differ 1997, 4:443-456.

50. Gabriel G, Dauber B, Wolff T, Planz O, Klenk HD, Stech J: The viral polymerase mediates adaptation of an avian influenza virus to a mammalian host. Proc Natl Acad Sci U S A 2005, 102:18590-18595.

51. Li Z, Chen H, Jiao P, Deng G, Tian G, Li Y, Hoffmann E, Webster RG, Matsuoka Y, Yu K: Molecular basis of replication of duck H5N1 influenza viruses in a mammalian mouse model. J Virol 2005, 79:12058-12064.

52. Hatta M, Gao P, Halfmann P, Kawaoka Y: Molecular basis for high virulence of Hong Kong H5N1 influenza A viruses. Science 2001, 293:1840-1842.

53. Gabriel G, Herwig A, Klenk HD: Interaction of polymerase subunit PB2 and NP with importin alpha1 is a determinant of host range of influenza $A$ virus. PLOS Pathog 2008, 4:e11.

54. Mehle A, Doudna JA: An inhibitory activity in human cells restricts the function of an avian-like influenza virus polymerase. Cell Host Microbe 2008, 4:111-122

55. Mehle A, Doudna JA: Adaptive strategies of the influenza virus polymerase for replication in humans. Proc Natl Acad Sci U S A 2009 106:21312-21316.
56. Neumann G, Watanabe $T$, Ito H, Watanabe $S$, Goto H, Gao P, Hughes M, Perez DR, Donis R, Hoffmann E, et al: Generation of influenza A viruses entirely from cloned cDNAs. Proc Natl Acad Sci U S A 1999, 96:9345-9350.

57. Sarmento L, Afonso CL, Estevez C, Wasilenko J, Pantin-Jackwood M: Differential host gene expression in cells infected with highly pathogenic H5N1 avian influenza viruses. Vet Immunol Immunopathol 2008, 125:291-302

58. Vester D, Rapp E, Gade D, Genzel Y, Reichl U: Quantitative analysis of cellular proteome alterations in human influenza $A$ virus-infected mammalian cell lines. Proteomics 2009, 9:3316-3327.

59. Kato $H$, Takeuchi O, Sato S, Yoneyama M, Yamamoto M, Matsui K, Uematsu S, Jung A, Kawai T, Ishii KJ, et al: Differential roles of MDA5 and RIG-I helicases in the recognition of RNA viruses. Nature 2006, 441:101-105.

60. Loo YM, Fornek J, Crochet N, Bajwa G, Perwitasari O, Martinez-Sobrido L, Akira S, Gill MA, Garcia-Sastre A, Katze MG, Gale M Jr: Distinct RIG-I and MDA5 signaling by RNA viruses in innate immunity. J Virol 2008, 82:335345

61. Yoneyama M, Fujita T: RNA recognition and signal transduction by RIG-I-like receptors. Immunol Rev 2009, 227:54-65.

62. Rehwinkel J, Tan CP, Goubau D, Schulz O, Pichlmair A, Bier K, Robb N, Vreede F, Barclay W, Fodor E, Reis e Sousax C: RIG-I detects viral genomic RNA during negative-strand RNA virus infection. Cell 2010, 140:397-408.

63. Haller $O$, Kochs $G$, Weber $F$ : The interferon response circuit: induction and suppression by pathogenic viruses. Virology 2006, 344:119-130.

64. Taniguchi T, Takaoka A: The interferon-alpha/beta system in antiviral responses: a multimodal machinery of gene regulation by the IRF family of transcription factors. Curr Opin Immunol 2002, 14:111-116.

65. Price GE, Gaszewska-Mastarlarz A, Moskophidis D: The role of alpha/beta and gamma interferons in development of immunity to influenza $A$ virus in mice. J Virol 2000, 74:3996-4003.

66. Mosca JD, Pitha PM: Transcriptional and posttranscriptional regulation of exogenous human beta interferon gene in simian cells defective in interferon synthesis. Mol Cell Biol 1986, 6:2279-2283.

67. Kuchipudi SV, Dunham SP, Nelli R, White GA, Coward VJ, Slomka MJ, Brown $\mathrm{H}$, Chang KC: Rapid death of duck cells infected with influenza: a potential mechanism for host resistance to H5N1. Immunol Cell Biol 2011.

68. Brydon EW, Morris SJ, Sweet C: Role of apoptosis and cytokines in influenza virus morbidity. FEMS Microbiol Rev 2005, 29:837-850.

69. Olsen CW, Kehren JC, Dybdahl-Sissoko NR, Hinshaw VS: bcl-2 alters influenza virus yield, spread, and hemagglutinin glycosylation. J Virol 1996, 70:663-666.

70. Wurzer WJ, Planz O, Ehrhardt C, Giner M, Silberzahn T, Pleschka S, Ludwig S: Caspase 3 activation is essential for efficient influenza virus propagation. EMBO J 2003, 22:2717-2728.

71. McLean JE, Datan E, Matassov D, Zakeri ZF: Lack of Bax prevents influenza A virus-induced apoptosis and causes diminished viral replication. J Virol 2009, 83:8233-8246.

72. Machida K, Tsukiyama-Kohara K, Seike E, Tone S, Shibasaki F, Shimizu M, Takahashi H, Hayashi Y, Funata N, Taya C, et al: Inhibition of cytochrome c release in Fas-mediated signaling pathway in transgenic mice induced to express hepatitis C viral proteins. J Biol Chem 2001, 276:12140-12146.

73. Pe'ery T, Mathews M: Viral translational strategies and host defense mechanism. In Translational Control of Gene Expression. Edited by Sonenberg N, Hershey J, Mathews M. Cold Spting Harbor: Cold Spting Harbor Laboratory Press; 2000:371-424.

74. McLean JE, Ruck A, Shirazian A, Pooyaei-Mehr F, Zakeri ZF: Viral manipulation of cell death. Curr Pharm Des 2008, 14:198-220.

75. Zamarin D, Garcia-Sastre A, Xiao X, Wang R, Palese P: Influenza virus PB1F2 protein induces cell death through mitochondrial ANT3 and VDAC1. PLoS Pathog 2005, 1:e4.

76. Zamarin D, Ortigoza MB, Palese P: Influenza A virus PB1-F2 protein contributes to viral pathogenesis in mice. J Virol 2006, 80:7976-7983.

77. Zhang S, Wang Q, Wang J, Mizumoto K, Toyoda T: Two mutations in the C-terminal domain of influenza virus RNA polymerase PB2 enhance transcription by enhancing cap-1 RNA binding activity. Biochim Biophys Acta 2012, 1819:78-83

78. Zhang S, Weng L, Geng L, Wang J, Zhou J, Deubel V Buchy P, Toyoda T: Biochemical and kinetic analysis of the influenza virus RNA polymerase purified from insect cells. Biochem Biophys Res Commun 2010, 391:570574 
79. Goto H, Wells K, Takada A, Kawaoka Y: Plasminogen-binding activity of neuraminidase determines the pathogenicity of influenza A virus. J Virol 2001, 75:9297-9301.

80. Yoneyama M, Suhara W, Fukuhara Y, Sato M, Ozato K, Fujita T: Autocrine amplification of type I interferon gene expression mediated by interferon stimulated gene factor 3 (ISGF3). J Biochem 1996, 120:160-169.

doi:10.1186/1743-422X-9-106

Cite this article as: Wang et al:: PA from an H5N1 highly pathogenic avian influenza virus activates viral transcription and replication and induces apoptosis and interferon expression at an early stage of infection. Virology Journal 2012 9:106.

\section{Submit your next manuscript to BioMed Central and take full advantage of:}

- Convenient online submission

- Thorough peer review

- No space constraints or color figure charges

- Immediate publication on acceptance

- Inclusion in PubMed, CAS, Scopus and Google Scholar

- Research which is freely available for redistribution 